\title{
Guidance for NIST Staff on Using Inclusive Language in Documentary Standards
}

NIST Standards Inclusivity Effort Team

Kathryn Miller

David Alderman

Lisa Carnahan

Lily Chen

Jim Foti

Barbara Goldstein

Mike Hogan

Jennifer Marshall

Karen Reczek

Nathalie Rioux

Mary F. Theofanos

David Wollman

This publication is available free of charge from: https://doi.org/10.6028/NIST.IR.8366

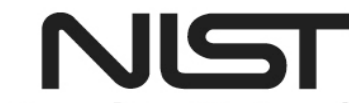

National Institute of Standards and Technology

U.S. Department of Commerce 


\title{
Guidance for NIST Staff on Using Inclusive Language in Documentary Standards
}

\author{
Kathryn Miller \\ Information Services Office \\ David Alderman \\ Jennifer Marshall \\ Karen Reczek \\ Nathalie Rioux \\ Standards Coordination Office \\ Lisa Carnahan \\ Lily Chen \\ Mike Hogan \\ Jim Foti \\ Information Technology Laboratory
}

\author{
Barbara Goldstein \\ Physical Measurement Laboratory \\ Mary F. Theofanos* \\ Material Measurement Laboratory \\ David Wollman \\ Engineering Laboratory
}

*Currently an employee in the Communications Technology Laboratory

This publication is available free of charge from:

https://doi.org/10.6028/NIST.IR.8366

April 2021

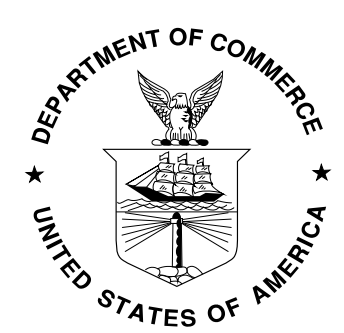

U.S. Department of Commerce Gina M. Raimondo, Secretary

National Institute of Standards and Technology James K. Olthoff, Performing the Non-Exclusive Functions and Duties of the Under Secretary of Commerce for Standards and Technology \& Director, National Institute of Standards and Technology 
Certain commercial entities, equipment, or materials may be identified in this document in order to describe an experimental procedure or concept adequately. Such identification is not intended to imply recommendation or endorsement by the National Institute of Standards and Technology, nor is it intended to imply that the entities, materials, or equipment are necessarily the best available for the purpose.

National Institute of Standards and Technology Interagency or Internal Report 8366

Natl. Inst. Stand. Technol. Interag. Intern. Rep. 8366, 15 pages (April 2021)

This publication is available free of charge from: https://doi.org/10.6028/NIST.IR.8366 


\title{
Preface
}

This is the first edition of this guidance. This guidance complements NISTIR 7854 Guidelines for NIST Staff Participating in Documentary Standards Developing Organizations' Activities, August 2012.

\begin{abstract}
This document provides guidance to NIST staff regarding the use of inclusive language in documentary standards and documents that support the realization and dissemination of physical standards; Standards Developing Organizations' (SDOs) policies and procedures; and standards development participation. The document is intended to be used as guidance by NIST standards participants seeking to be impactful in addressing these issues.
\end{abstract}

\section{Key words}

bias-free language; documentary standards; inclusive language; standards committee participation; standards developing organizations; voluntary consensus standards. 


\section{Acknowledgements}

In July 2020, the NIST Standards Inclusivity Effort (SIE) Team (aka the SIE Team) was established to develop guidance for NIST staff on using inclusive language when participating in standards development activities. The SIE Team Co-conveners were David Alderman and Lisa Carnahan.

From the start, the focus of the SIE Team was to develop this guidance publication. This publication reflects the contributions and extensive discussions by the SIE Team. The team researched inclusive language concepts; learned of similar activities within NIST and externally; and sought feedback from our NIST colleagues. The team hosted a NIST internal virtual meeting on October 6, 2020 to discuss this topic with 125 attendees. A call for comments on a draft of this publication was made to NIST staff. After addressing comments from staff, the next draft of this publication was sent to the following NIST groups and offices for comment: Civil Rights and Diversity Office; Physical Measurement Laboratory APS-IDEA (American Physical Society - Inclusion, Diversity, and Equity Alliance); Engineering Laboratory DIB Council (Diversity, Inclusion \& Belonging); Employee Resource Council; PEAR (Postdoc and Early-Career Association of Researchers); NIST Association for Black Staff; Association of NIST Asian Pacific Americans; NIST and NOAA Pride; Association of NIST Hispanic Americans; NIST Parents Network; Women in STEM (WiSTEM); Toastmasters; DISTEM FORUM; NIST Chapter of Sigma Xi; Lactation Support Group; and Boulder Association of Women in Science.

The SIE Team would like to express its deep appreciation for the comments that were received. Those thoughtful comments have enhanced the organization, content, and clarity of this publication. The editors for this publication are Kathryn Miller and Mike Hogan.

The SIE Team members are:

David Alderman, Standards Coordination Office

Lisa Carnahan, Information Technology Laboratory

Lily Chen, Information Technology Laboratory

Jim Foti, Information Technology Laboratory

Barbara Goldstein, Physical Measurement Laboratory

Mike Hogan, Information Technology Laboratory

Jennifer Marshall, Standards Coordination Office

Kathryn Miller, Information Services Office

Karen Reczek, Standards Coordination Office

Nathalie Rioux, Standards Coordination Office

Mary F. Theofanos, Material Measurement Laboratory (Currently an employee in the Communications Technology Laboratory)

David Wollman, Engineering Laboratory 


\section{Table of Contents}

1. Introduction ................................................................................................................................... 1

2. Purpose of Document ....................................................................................................... 1

3. Benefits of Inclusive Language ................................................................................................ 1

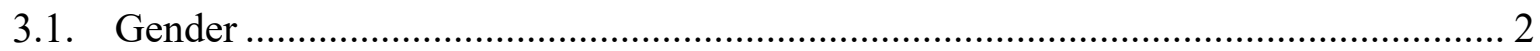

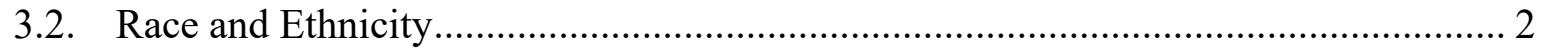

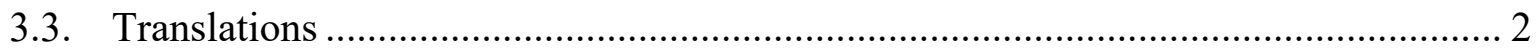

4. Inclusivity Guidance.............................................................................................................. 3

4.1. NIST Technical Series Publications Author Instructions............................................ 3

4.2. American Psychological Association (APA) Style and Grammar Guidelines............ 5

4.3. Chicago Manual of Style (CMoS) ..................................................................... 5

5. SDO Guidance.................................................................................................................. 6

5.1. ASTM International (Formerly known as American Society for Testing and Materials)

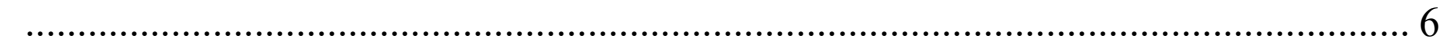

5.2. Institute of Electrical and Electronics Engineers (IEEE) ........................................... 6

5.3. Internet Engineering Task Force (IETF) .......................................................... 6

5.4. InterNational Committee for Information Technology Standards (INCITS).............. 7

5.5. International Organization for Standardization and the International Electrotechnical

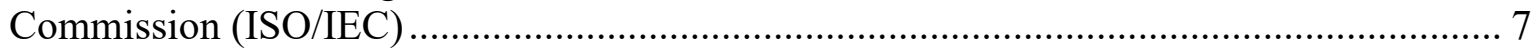

6. Industry Guidance.............................................................................................................. 8

7. Bibliography ................................................................................................................... 8 


\section{Introduction}

Inclusive, or bias-free, language uses expressions and terms that are likely to be perceived as neutral or welcoming by everyone, regardless of their gender, race, religion, age, etc. Using inclusive language can help people from diverse backgrounds feel more welcome and encourages precise, high quality work. As noted in a recent McKinsey survey, employees who feel more included are nearly three times more likely to feel excited by, and committed to, their organizations.

This guidance is based upon three sources: NIST Technical Series Publications Author Instructions; the American Psychological Association Style Guide; and the Chicago Manual of Style. These sources provide suggestions on inclusive language, including examples of words or expressions to avoid. As guidance, this provides standards participants with a tool to assist in how to apply these suggestions to their work.

Also, information on inclusive language policies and guidance by various Standards Developing Organizations (SDOs) is included.

This guidance, including examples, reflects current understanding and may be updated as the field evolves.

\section{Purpose of Document}

This document provides guidance to NIST staff for the consistent use of inclusive language in:

1. developing documentary standards;

2. using inclusive language during verbal exchanges, such as during negotiations to reach consensus at standards development meetings; and

3. developing documents supporting realization and dissemination of physical standards.

This guidance is limited to the English language, but the concepts can be applied more broadly such as in translations.

\section{Benefits of Inclusive Language}

Using inclusive language - in both our speech and writing - during the development of documentary standards can positively impact those who develop, read, and implement those standards. Such language: ${ }^{1}$

1. avoids false assumptions and permits more precise wording,

2. conveys respect to those who listen or read,

3. maintains neutrality, avoiding unpleasant emotions or connotations brought on by more divisive language (e.g., the term 'elderly' may have different connotations based on the age of an employee),

4. removes colloquialisms that are exclusive or usually not well understood by all (e.g., drink the Kool-Aid), and

5. enables all to feel included in the topic discussed.

${ }^{1}$ APA Publication Manual, Seventh Edition, Chapter 5: Bias-Free Language. Available at: https://apastyle.apa.org/style-grammarguidelines/bias-free-language 
In order to gain these and other benefits, many organizations, including those described in Sections 5 and 6, are changing expressions and terms to remove biased language. The following guidance is intended to help NIST staff advocate for the consistent use of inclusive language in documentary standards being developed by Standards Developing Organizations (SDOs), Standards Setting Organizations (SSOs), consortia, and federal agencies. Additionally, this guidance should help NIST staff developing documents that support the realization and dissemination of physical standards.

Inclusive language should be considered when drafting new standards, and the language in existing standards should be assessed during periodic reviews to determine whether more inclusive alternatives could be used when the standard is revised or amended.

\subsection{Gender}

While gender-neutral language is important for achieving inclusive language in documentary standards, a lack of awareness of the importance of gender in the development and design of standards can lead to the publication of standards that are not responsive to all users (genders). Gender-neutral language does not imply that the standards are developed without considering gender-specific needs and priorities. Gender-neutral language does not remedy the use of genderbiased data and reference models in the design, development, and maintenance of standards. Appropriate use of gender/non-biased data is a predecessor to gender-neutral inclusive language.

\subsection{Race and Ethnicity}

Inclusive language recognizes that language should be perceived as neutral by everyone regardless of their race and/or ethnicity. Yet a lack of understanding in defining race and ethnicity as a variable can result in publication of standards that are not responsive to all users. Sociologist Tukufu Zuberi argues that "race is a socially complex matter and that subjective predisposition and biases, more than biology or demography, govern our definitions of racial differences" (White Logic, White Methods, p. 12). Since race is a social construct it is difficult to measure. Yet data is critical to the development of standards; thus data collection must be assessed for unintended biases. Depending on the purpose, consider data collection efforts that focus on measurable characteristics such as a range of skin color, rather than race, as the variable with assigned values such as Caucasian, Asian, Native American, African American, among others. For example, in studies of proper lighting for biometrics applications like face recognition, race is sometimes used as a proxy for skin tone. On the other hand, research studies and the resulting standards related to medical conditions using race or gender may be appropriate, such as thalassemia for those of Mediterranean descent or sickle cell disease for those of African descent. Appropriate collection and use of non-biased data will help support the development of unbiased standards and inclusive language in them.

\subsection{Translations}

Standards are drafted and finalized in the English language for most of the efforts in which NIST researchers participate. Many SDOs then translate standards from English into multiple languages. The concerns of inclusivity carry forward when standards are translated. NIST staff should encourage SDOs to develop and apply inclusivity policies and procedures to these translations. 


\section{Inclusivity Guidance}

The following three sources of inclusive language guidance are recommended as resources for further guidance to help NIST staff consistently use inclusive language in standards development. The use of these resources is optional. NIST staff should determine applicability for their specific circumstances.

\subsection{NIST Technical Series Publications Author Instructions}

The following is taken from the 'Inclusive Language' section of the April 2021 version of the NIST Technical Series Publications Author Instructions. It is not official NIST guidance and will be updated periodically based on user feedback.

- Industry terminology is rapidly changing to avoid biased language, and NIST would like to support this evolution. With that in mind, consider "good usage" of words versus "common usage." Ask yourself: Is the use of this term or phrase central to the meaning of the work? Can I convey the intended meaning using more inclusive language?

- Consider the context of your research as you read these guidelines; they will not apply to every situation. Additionally, you should monitor your industry for ongoing discussions regarding acceptable language, since preferred terminology may change within a given field over time.

- It is possible that avoiding potentially biased terms will introduce comprehension issues. These are guidelines to assist authors in writing NIST Technical Series Publications, they are not requirements. Consult with your OU leadership if you are unsure about language and terminology.

- Avoid terms that use 'black' to mean something bad or negative and 'white' to mean positive or less harmful

○ Examples: blacklist/whitelist; blackmail; white lie

- Avoid terms that perpetuate negative stereotypes or unequal power relationships

- Examples: master/slave; smart/dumb; right/left ${ }^{2}$

- Avoid terms that assign a gender or sex to inanimate objects

○ Examples: male/female connectors; male bolt/female nut

- Avoid colloquialisms, metaphors, similes, idioms, and other unnecessary jargon. Plain language ${ }^{3}$ is always preferable.

- Do not identify gender or sex unless necessary for comprehension, or when referring to a specific individual or group.

- Use people-first language when describing a specific individual or group, unless that individual or group clearly prefers identity-first language. The goal is to avoid terms that are condescending or reductive. ${ }^{4}$

- People-first language: persons experiencing homelessness; persons with a disability; adult who uses a wheelchair

- Identity-first language: Deaf person; blind person; wheelchair user

\footnotetext{
${ }^{2}$ In this example, avoid using right to mean "good" or "normal," and left to mean "bad" or "abnormal."

${ }^{3}$ See official guidelines for the Plain Writing Act of 2010.

${ }^{4}$ The APA Style and Grammar Guidelines section on Disability has a useful discussion on choosing between person-first and identity-first language.
} 
- Pay attention to the order in which you present groups of people (including authors, contributors, social groups, agencies, etc.). The order can imply that the first mentioned dominates the later mentioned.

- When referring to persons in the text (i.e., in the acknowledgments), it is recommended to ask them how they would like to be named. This could include asking for their full names, prefixes, and/or pronouns.

Table 1 was extracted in part to show examples of sentences with potentially biased language along with suggestions for unbiased alternatives. The full table can be found on the NIST website.

Table 1. Examples of potentially biased language in historical NIST Technical Series Publications.

\begin{tabular}{|c|c|}
\hline Original & Suggested Edits \\
\hline $\begin{array}{l}\text { Application whitelisting technologies use whitelists } \\
\text { to control which applications are permitted to execute } \\
\text { on a host. }\end{array}$ & $\begin{array}{l}\text { Application control technologies use allowlists to } \\
\text { control which applications are permitted to execute on } \\
\text { a host. }\end{array}$ \\
\hline $\begin{array}{l}\text { This is critical to various aspects of security, including } \\
\text { the black list of certificates pushed by the product } \\
\text { vendors. }\end{array}$ & $\begin{array}{l}\text { This is critical to various aspects of security, including } \\
\text { the denylisting of certificates pushed by the product } \\
\text { vendors. }\end{array}$ \\
\hline $\begin{array}{l}\text { Moreover, affected individuals can be subject to } \\
\text { embarrassment, identity theft, or blackmail as the } \\
\text { result of a breach involving PII. }\end{array}$ & $\begin{array}{l}\text { Moreover, affected individuals can be subject to } \\
\text { embarrassment, identity theft, or extortion as the result } \\
\text { of a breach involving PII. }\end{array}$ \\
\hline $\begin{array}{l}\text { If a master data node fails, the system can } \\
\text { automatically switch over and begin to use one of the } \\
\text { slave nodes. }\end{array}$ & $\begin{array}{l}\text { If a primary data node fails, the system can } \\
\text { automatically switch over and begin to use one of the } \\
\text { secondary nodes. }\end{array}$ \\
\hline $\begin{array}{l}\text { They were usually very limited tests of some groups to } \\
\text { see how well they were performing measurements, but } \\
\text { in every case we found that there were some people } \\
\text { who were way out in left field as far as the accuracies } \\
\text { of their measurements were concerned. }\end{array}$ & $\begin{array}{l}\text { They were usually very limited tests of some groups to } \\
\text { see how well they were performing measurements, but } \\
\text { in every case, we found that there were some people } \\
\text { who made very inaccurate measurements. }\end{array}$ \\
\hline $\begin{array}{l}\text { To measure reflected intermodulation, participants } \\
\text { were instructed to connect the male connector of the } \\
\text { artifact to the active test port of their system and the } \\
\text { female connector of the artifact to a low PIM load. }\end{array}$ & $\begin{array}{l}\text { To measure reflected intermodulation, participants } \\
\text { were instructed to connect the plug of the artifact to the } \\
\text { active test port of their system and the socket of the } \\
\text { artifact to a low PIM load. }\end{array}$ \\
\hline $\begin{array}{l}\text { And sometimes we complain that measurement } \\
\text { standards work cannot get management attention or } \\
\text { that it is too low on the priority totem pole. }\end{array}$ & $\begin{array}{l}\text { And sometimes we complain that measurement } \\
\text { standards work cannot get management attention or } \\
\text { that it is a low priority. }\end{array}$ \\
\hline $\begin{array}{l}\text { The evaluator, however, can measure a written } \\
\text { exercise, a skill demonstration... he/she cannot take the } \\
\text { student's word for the learned skill... }\end{array}$ & $\begin{array}{l}\text { The evaluator, however, can measure a written } \\
\text { exercise, a skill demonstration... they cannot take the } \\
\text { student's word for the learned skill... }\end{array}$ \\
\hline $\begin{array}{l}\text { The unprecedented level of destruction by storm surge } \\
\text { in Mississippi and Louisiana brought renewed focus on } \\
\text { the need to address natural disasters, in addition to } \\
\text { protection from manmade hazards. }\end{array}$ & $\begin{array}{l}\text { The unprecedented level of destruction by storm surge } \\
\text { in Mississippi and Louisiana brought renewed focus on } \\
\text { the need to address natural disasters, in addition to } \\
\text { protection from hazards caused by humans. }\end{array}$ \\
\hline $\begin{array}{l}\text { Standardization establishes the baseline mindset, and } \\
\text { without them, meaningful forward progress is } \\
\text { handicapped. }\end{array}$ & $\begin{array}{l}\text { Standardization establishes the baseline mindset, and } \\
\text { without them, meaningful forward progress is } \\
\text { impeded. }\end{array}$ \\
\hline $\begin{array}{l}\text { Moreover, if the reallocation violates principles of } \\
\text { equity (fairness), the outcomes can be adjusted by } \\
\text { income or material transfers to the needy. }\end{array}$ & $\begin{array}{l}\text { Moreover, if the reallocation violates principles of } \\
\text { equity (fairness), the outcomes can be adjusted by } \\
\text { income or material transfers to persons experiencing } \\
\text { material poverty. }\end{array}$ \\
\hline
\end{tabular}




\subsection{American Psychological Association (APA) Style and Grammar Guidelines}

The APA Style and Grammar Guidelines includes extensive guidance on Bias-Free Language.

The APA bias-free language guidance emphasizes the importance of bias-free and inclusive language and the importance of reviewing writings for appropriate language usage. It contains both general and specific guidance.

The APA bias-free language guidance is organized into the following topics:

- General Principles for Reducing Bias

- Historical Context

- Age

- Disability

- Gender

- Participation in Research

- Racial and Ethnic Identity

- Sexual Orientation

- Socioeconomic Status

- Intersectionality

\subsection{Chicago Manual of Style (CMoS)}

When connected to the NIST network, NIST staff have access to the $17^{\text {th }}$ Edition of The Chicago Manual of Style Online. Sections 5.251 - 5.260 cover Bias-Free Language.

NIST staff are cautioned to avoid this guidance with respect to two issues.

1. The guidance is in conflict with other sources that recommend the use of the singular "they" in place of "he" and "she." The singular "they" is now becoming an accepted generic third-person singular pronoun in English. Use of the singular "they" is endorsed by the APA Style and Grammar Guidelines because it is inclusive of all people and helps writers avoid making assumptions about gender.

2. Many CMoS examples treat gender as binary. This omits people whose gender identity does not fit within the traditional male/female binary.

The guidance on how to remove personal pronouns altogether provides good examples.

The bias-free language guidance is organized into the following topics:

- 5.251 Maintaining Credibility

- 5.252 Gender Bias

- 5.253 Other Biases

- 5.254 Bias and the Editor's Responsibility

- 5.255 Techniques for Achieving Gender Neutrality

- 5.256 Gender-neutral Singular Pronouns 
- 5.257: Problematic Gender-specific Suffixes

- 5.258: Necessary Gender-specific Language

- 5.259: Sex-specific Labels as Adjectives

- 5.260 Avoiding Other Biased Language

\section{SDO Guidance}

If an SDO has specific guidance on inclusive language, NIST staff are responsible for knowing and following that guidance. Further, in the absence of SDO guidance, NIST staff may use the guidance and references mentioned in this document to identify any expressions or terms that may be perceived as non-inclusive, ambiguous, or unnecessarily colloquial.

Examples of SDO guidance on inclusive language or inclusivity policies are listed below.

\subsection{ASTM International (Formerly known as American Society for Testing and Materials)}

ASTM International is forming an ASTM International Diversity and Inclusion Council. This group will work to broadly address diversity and inclusion across the staff, membership, and governance of ASTM International. See: Valuing Every Voice.

Note that this activity does not directly address the use of inclusive language in the ASTM standards.

\subsection{Institute of Electrical and Electronics Engineers (IEEE)}

The IEEE Standards Association is presently taking a bottom-up approach to addressing the use of inclusive language in the IEEE standards, leaving it up to each individual project to address as needed.

An example of one project that has discussed avoiding biased terms (such as master/slave) is: IEEE 1588-2019 - IEEE Standard for a Precision Clock Synchronization Protocol for Networked Measurement and Control Systems.

\subsection{Internet Engineering Task Force (IETF)}

The IETF has been addressing the use of inclusive language in their standards and Requests for Comments (RFCs).

Terminology, Power, and Inclusive Language in Internet-Drafts and RFCs is currently an internet draft that does not reflect IETF consensus. This document suggests how editors of Internet-Drafts and RFCs can and should avoid exclusionary language and incorporate alternative, inclusive language in order to improve technical IETF documentation.

Additionally, the IETF has a "work-in-progress" GitHub site on Inclusive Terminology in IETF Documents. Besides offering some basic guidance to authors and reviewers of IETF publications, it identifies terms and alternatives being used by many technology organizations, and links to those efforts. 


\subsection{InterNational Committee for Information Technology Standards (INCITS)}

INCITS has approved the following INCITS Principle of Inclusive Terminology and is developing a guidance document to support this policy.

\section{"INCITS Principle of Inclusive Terminology}

Whenever possible, inclusive terminology shall be used to describe technical capabilities and relationships. Insensitive, archaic and non-inclusive terms shall be avoided.

For the purpose of this Principle, "inclusive terminology" means terminology perceived or likely to be perceived as neutral or welcoming by everyone, regardless of their sex, gender, race, color, religion, etc.

\section{EXAMPLES}

The terms "master/slave" to describe a model where one device or process controls another as subordinate should be avoided. Alternatives such as "main/secondary", "primary/secondary", "primary/replica", "host/target", "leader/follower", "orchestrator/worker", "initiator/responder" or similar descriptive terminology should be used as applicable and where possible.

The terms "blacklist" to describe something (i.e., users, websites, emails, or applications) blocked or not permitted and "whitelist" to describe counterparts that are allowed or accepted, should be avoided. Alternatives such as "blocklist/passlist", "denylist/allowlist", "permitted/refused" or similar descriptive terminology should be used as applicable and where possible.

New specifications, standards, documentation and other collateral shall be developed using inclusive terminology. As feasible, existing and legacy specifications and documentation shall be updated to identify and replace non-inclusive terms with alternatives more descriptive and tailored to the technical capability or relationship."

\subsection{International Organization for Standardization and the International Electrotechnical Commission (ISO/IEC)}

ISO and IEC have formed a Joint Strategic Advisory Group (JSAG) to promote development of standards that consider needs of all users. ANSI established the Virtual Technical Advisory Group (VTAG) to provide U.S. input to the ISO/IEC JSAG on Gender Responsive Standards.

The present guidance and requirements for drafting ISO/IEC publications is in the ISO/IEC Directives, Part 2 - Principles and rules for the structure and drafting of ISO and IEC documents, Eighth edition, 2018. This document does not address inclusive language. A companion document, ISO House Style, specifies the language, formatting, and presentation of ISO documents: editorial elements that are outside the scope of the ISO/IEC Directives, Part 2. There is a section on Inclusive Language.

Additionally, the Strategic Advisory Group (SAG) on accessibility submitted its final report and recommendations at a September 2020 meeting. These recommendations include a forthcoming toolkit to ensure future standards will take accessibility into consideration. 


\section{Industry Guidance}

In addition to SDOs, several technical organizations and companies have also provided guidance to promote use of inclusive language. Examples include Google's guidance on writing inclusive documentation, Google Android Open Source Project's guidance on coding with respect, and Microsoft's guidance on bias-free communications. These guidance documents cover topics such as avoiding ableist language (e.g., use placeholder variable instead of dummy variable), avoiding unnecessarily gendered language (e.g., use person-hours instead of man-hours), and avoiding terms which may carry unconscious racial bias or terms associated with military actions, politics, or historical events (e.g., use 'stop responding' instead of 'hang', and use 'perimeter network' instead of 'demilitarized zone'). As an implementation example, Microsoft's GitHub, which provides hosting for software development and version control, is working to rename the default branch of its repositories from 'master branch' to 'main branch'.

\section{Bibliography}

This bibliography lists additional relevant publications that may help to further inform readers of this report.

ASME Y14.44-2008: Reference Designations for Electrical and Electronics Parts and Equipment: Engineering Drawing and Related Documentation Practices. Available at https://www.asme.org/getmedia/d7022288-0a4f-4557-b7b1-363b7b9b7ad4/17014.pdf

Committee on the Status of Women in Linguistics (COSWL), Linguistic Society of America (LSA) (2016) Guidelines for inclusive language. Available at https://web.archive.org/web/20201014112058/https://www.linguisticsociety.org/resource/guideli nes-inclusive-language

Eglash R (2007) Broken metaphor: the master-slave analogy in technical literature. Technology and Culture 48(2):360-369. Available at https://www.jstor.org/stable/40061475

General Services Administration (GSA) (2020) 18F content guide. Available at https://web.archive.org/web/20201014111946/https://content-guide.18f.gov/our-approach/

Kelly R (2018) A list of offensive (exclusionary) words used in job descriptions. Ongig. Available at https://web.archive.org/web/20201009135248/https://blog.ongig.com/writing-jobdescriptions/a-list-of-offensive-exclusionary-words-used-in-job-descriptions/

McKinsey \& Company (2020) How organizations can foster an inclusive workplace. Available at https://web.archive.org/web/20201013191440/https://www.mckinsey.com/businessfunctions/organization/our-insights/understanding-organizational-barriers-to-a-more-inclusiveworkplace\#

MyPronouns.org (2020) Inclusive Language. Available at https://web.archive.org/web/20201006123839/https://www.mypronouns.org/inclusivelanguage

Plain Language Action and Information Network (PLAIN) (2020) Plain language guidelines. Available at https://web.archive.org/web/20201007205450/https://plainlanguage.gov/ 
Purdue Writing Lab (2020) Using appropriate language. Available at https://web.archive.org/web/20201009134311/https://owl.purdue.edu/owl/general_writing/acade mic_writing/using_appropriate_language/index.html

SumOfUs (2016) A Progressive's style guide. Available at https://web.archive.org/web/20201001105254/https://s3.amazonaws.com/s3.sumofus.org/images /SUMOFUS_PROGRESSIVE-STYLEGUIDE.pdf

Weber JH (2012) Gender-neutral technical writing. TechWhirl. Available at https://web.archive.org/web/20200606165126/https://techwhirl.com/gender-neutral-technicalwriting/

Zuberi T, Bonilla-Silva E (2008) White Logic, White Methods: Racism and Methodology (Rowman \& Littlefield Publishers). 